\title{
Haemodialysis related osteomalacia: a staining method to demonstrate aluminium
}

\author{
MALCOLM RC BUCHANAN, BENNO U IHLE, CHERYL M DUNN \\ From the Departments of Anatomical Pathology and Nephrology, Royal Melbourne Hospital, \\ Parkville 3050, Victoria, Australia
}

SUMMARY A slight modification in tissue processing and staining technique enables a previously $\frac{?}{8}$ described method for staining aluminium to be used to demonstrate aluminium in osteomalacia $i$ associated with haemodialysis. The stain appears to be accurate in diagnosing this condition and may assist in establishing the diagnosis before severe osteomalacia develops.

A severe, treatment-resistant, form of osteomalacia has been seen to be associated with long-term haemodialysis in the treatment of chronic renal failure. ${ }^{1}$ Initially recognised only in a few areas, which were later all shown to have high aluminium concentrations in the water supply used for the dialysate, it is now recognised to be more widespread. In all cases, however, chemical assay of bone samples reveals an unusually high aluminium content. ${ }^{2}$

Histological examination of bone from these patients shows that, unlike typical uraemic renal osteodystrophy, there is little or no evidence of osteitis fibrosa, but there is a marked increase in osteoid.

Irwin's stain for aluminium, as described by Lillie and Fullmer, ${ }^{3}$ was initially devised to demonstrate aluminium in paraffin-embedded lung tissue. As aluminium is removed during acid demineralisation of bone, it was necessary to modify this stain to make it suitable for use with epoxy resin-embedded, undecalcified bone. It has been previously stated that the staining reagent (aurine tricarboxylic acid), is specific for aluminium. ${ }^{4}$

\section{Material and methods}

Thirty-two iliac crest bone biopsies (cancellous bone) were obtained from 32 patients receiving haemodialysis. Portions of each biopsy were submitted for chemical assay and the remainder of the biopsy was fixed in $10 \%$ buffered formalin for 24 hours. After dehydration in acetone and infiltration, the biopsy samples were embedded in Araldite Epon. Sections $(4 \mu \mathrm{m})$ were cut with a steel knife using a Jung 1130 Biocut microtone. Sections were stained with haema-

Accepted for publication 23 March 1981 toxylin and eosin, von Kossa's stain and the stain for 은 aluminium. The Araldite Epon epoxy resin is not removed prior to staining.

STAINING METHOD FOR ALUMINIUM

1 Stain sections for $30 \mathrm{~min}$ in a $2 \%$ aurine tricarboxylic acid (ammonium salt) at $75^{\circ} \mathrm{C}$ in pH 5.2 buffer consisting of 3.8 parts of $5 \mathrm{M}$ ammonium chloride 3.8 parts $5 M$ ammonium acetate and 1 part 6 hydrochloric acid.

2 Wash in distilled water.

3 Decolorise for $25 \mathrm{~s}$ in a pH 7.2 buffer consisting of 3.6 parts of the above buffer and 10 parts of $1.6 \mathrm{M}$ ammonium hydrogen carbonate.

4 Wash in distilled water.

5 Counterstain in a saturated picric acid solution.

6 Dry sections and mount.

Normal (negative) control bone was obtained from necropsies on six patients with no evidence of renal disease.

\section{Results}

With this technique, mineralised bone stains a rusty brown colour while osteoid and the background stain yellow. Aluminium is a brilliant red colour.

Negative controls consistently showed no staining for aluminium.

In the biopsy group, assessment of bone disease was made using haematoxylin and eosin and von Kossa-stained sections. Biopsies having increased $C$ osteoid with increased numbers of birefringent laminae were interpreted as having osteomalacia. Those with increased number of osteoclasts, in- $\mathbb{D}$ creased number and size of osteoblasts and marrow fibrosis were interpreted as having osteitis fibrosa or $\frac{T}{2}$ changes of secondary hyperparathyroidism. When 
these findings were compared to the results of the aluminium stain, a number of patterns emerged.

In nine patients with varying degrees of osteomalacia, there was little or no evidence of osteitis fibrosa. In these patients, there was positive staining for aluminium. The stain was seen constantly at the junction between mineralised bone and osteoid but varied considerably in intensity (Figure). In all of these nine patients, chemical assays of bone showed higher levels of aluminium than normal.

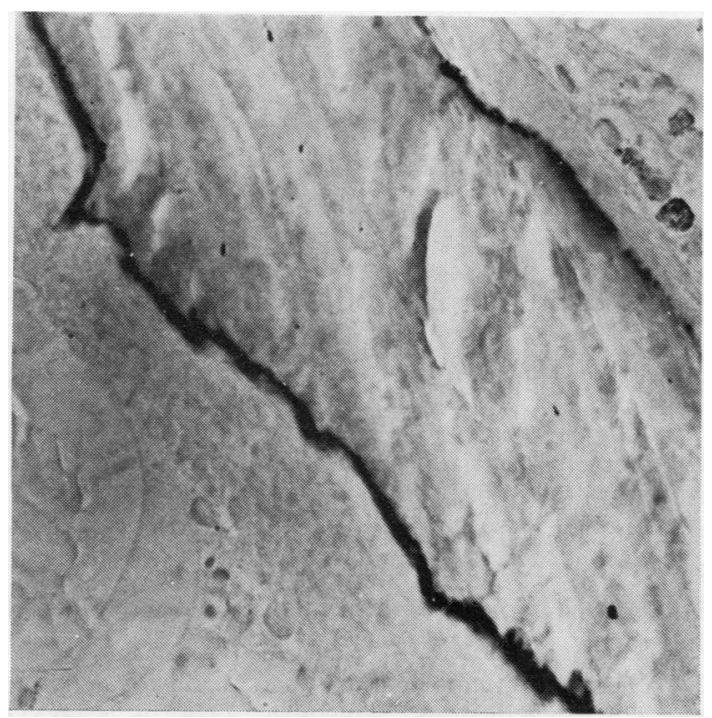

(a) $A$ bone trabeculum stained by the method described. The black line is the positive aluminium stain $\times 400$.

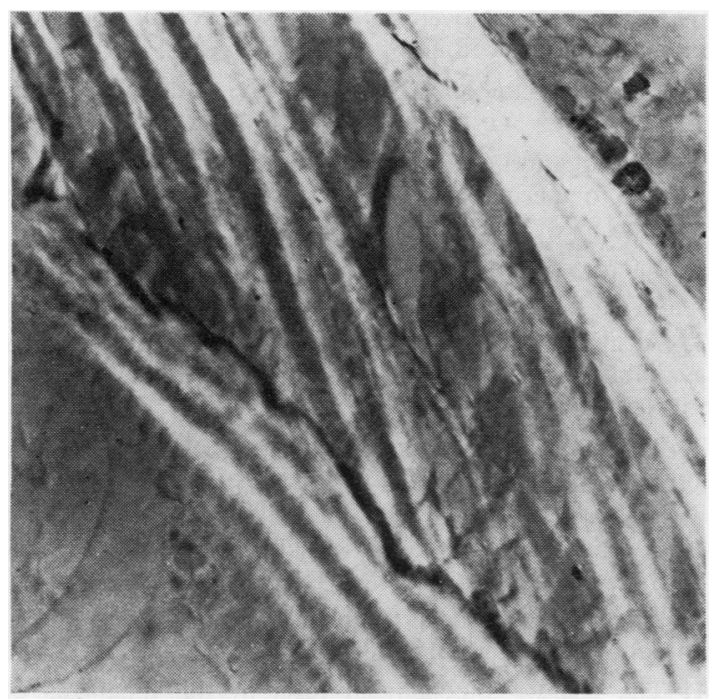

(b) the same field viewed with polarised light showing the birefringent laminae of the increased osteoid $\times 400$.
In six further patients, the stain for aluminium was also positive and was again seen to be mostly at the junction of the bone and osteoid. In these six biopsies, however, while all showed a marked increase in osteoid, there was also evidence of hyperparathyroidism. Chemical assay of bone from these patients for aluminium also produced higher than normal values for aluminium.

In the remaining 17 bone biopsies, no staining for aluminium was seen. Most of these biopsies showed less evidence of osteomalacia and all had changes of osteitis fibrosa. Assay in this group was variable, with above normal to very high quantities of aluminium being seen.

Repeating the stain on many of the biopsies showed a high degree of reproducibility.

\section{Discussion}

We have described a technique to demonstrate aluminium in epoxy resin-embedded bone biopsies. Wc have only been able to obtain satisfactory results with this staining method when the material has been embedded in Araldite Epon. With other epoxy resins as embedding media (Spurr's Epon, glycol methacrylate), we have had variable results. The significance of this finding is uncertain. Because of the solubility of aluminium at high $\mathrm{pH}$, sodium ethoxide, which is normally used to remove resin in this laboratory, was not used. The stain is negative if the resin is removed by this method. We have no experience with other resin-removing substances.

The mechanism by which progressive demineralisation develops in the bone of patients receiving haemodialysis is unknown, as is the relation to aluminium. Ellis et al. ${ }^{5}$ have demonstrated that the severity of osteomalacia in these patients is unrelated to aluminium concentration in the bone and our experience with this staining technique appears to confirm this finding. They were able to show, however, that parenteral aluminium given to rats caused demineralisation at the epiphyseal growth plate and in the adjacent diaphysis. They felt that this finding may indicate a direct effect of aluminium on bone. The constant position of stain at the bone-osteoid junction in our series may be interpreted as supporting this suggestion. In further such experimental studies, we suggest that this stain may be a useful aid in assessing the effect of aluminium.

The diagnosis of haemodialysis-related osteomalacia is by clinical, biochemical and histological assessment. We feel that the aurine tricarboxylic acid stain for aluminium in bone aids in identifying these patients and may reduce the need for bone aluminium assay in establishing the diagnosis. Furthermore it is probably a useful clinical tool for early - that is, 
presymptomatic, diagnosis of aluminium-related bone disease.

\section{References}

${ }^{1}$ Pierides AM, Edwards Jr WG, Cullum Jr UX, McCall JT, Ellis HA. Haemodialysis encephalopathy with osteomalacic fractures and muscle weakness. Kidney Int 1980;18:115-24.

2 Parson V, Davies C, Goode C, Ogg C, Siddiavi J. Aluminium in bone from patients with renal failure. $\mathrm{Br}$ Med $J$ $1971 ;$ ii :273-5.

${ }^{3}$ Lillie RD, Fullmer HM. Histopathologic technique and practical histochemistry. 4th ed. New York: McGraw-Hill, 1976.

4 Gammett LP, Sottery CT. A new reagent for aluminium. Journal of the American Chemistry Society 1925;47:142-3.

${ }^{5}$ Ellis HA, McCarthy JH, Herrington J. Bone aluminium in haemodialysed patients and in rats injected with aluminium chloride: relationship to impaired bone mineralisation. J Clin Pathol 1979;32:832-44.

Requests for reprints to: Dr MRC Buchanan, Department of Anatomical Pathology, Royal Melbourne Hospital, Parkville, 3050, Victoria, Australia.

\section{Reports and Bulletins prepared by the Association of Clinical Biochemists}

The following reports and bulletins are published by the Association of Clinical Biochemists. They may be obtained from The Publishing Department, British Medical Journal (ACB Technical Bulletins), BMA House, Tavistock Square, London WC1H 9JR. Overseas readers should remit by British Postal or Money Order.

SCIENTIFIC REVIEWS (price $£ 1 \cdot 00 / \$ 2.00$ each)

1 The assessment of thyroid function March 1971 FV FLYNN and JR HOBBS

2 Renal function tests suitable for clinical practice January 1972 FL MITCHELL, N VEALL, and RWE WATTS

3 Biochemical tests for the assessment of fetoplacental function May 1975 CE WILDE and RE OAKEY

4 Test of exocrine pancreatic function March 1977 AH GOWENLOCK

5 Assay of cholinesterase in clinical chemistry March 1979 ELSIE SILK, J KING, and MARY WHITTAKER

TECHNICAL BULLETINS (price $£ 1 \cdot 00 / \$ 2.00$ each)

22 Bilirubin standards and the determination of bilirubin by manual and technicon AutoAnalyzer methods January 1971 BARBARA BILLING, RUTH HASLAM, and N WALD

23 Interchangeable cells for spectrophotometers and fluorimeters September 1971 SS BROWN and AH GOWENLOCK

24 Simple tests to detect poisons March 1972 BW MEADE et al.

25 Blood gas analysers May 1972 K DIxoN

26 Kits for enzyme activity determination September 1972 SB ROSALKI and D TARLOW

27 Assessment of pumps suitable for incorporation into existing continuous flow analytical systems November 1972 A FLECK et al.

28 Routine clinical measurements of transferrin in human serum September 1973 K DIXON
29 Control materials for clinical biochemistry (5th edition) September 1973 JF STEVENS

30 Notes on the quality of performance of serum cholesterol assays September 1973 SS BROWN

31 Determination of uric acid in blood and in urine July 1974 RWE WATTS

32 A survey of amino acid analysers readily available in the United Kingdom September 1974 JE CARL.YLE and P PURKISS

33 Definitions of some words and terms used in automated analysis November 1974 A FLECK, R ROBINSON, SS BROWN, and JR HOBBS

34 Measurement of albumin in the sera of patients January 1975 LINDA SLATER, PM CARTER, and JR HOBBS 35 Investigation of the validity of temperature correction factors for serum aspartate and alanine transaminases March 1975 SB ROSALKI et al.

36 Factors influencing the assay of creatinine November 1975 JGH COOK

37 A survey of enzyme reaction rate analysers readily available in the United Kingdom July 1977 RA SAUNDERS and RF BURNS

38 Transport of specimens for clinical chemistry analysis November 1977 P WILDING, JF ZILVA, and CE WILDE

39 A scheme for the evaluation of diagnostic kits May 1978 PH LLOYD

40 A practical guide to gamma-counting in radioimmunoassay January 1980 CE WILDE and D OTTEWELL

41 The use of biochemical tests in the diagnosis of disorders of calcium metabolism July 1980 ANGELA FAIRNEY 